\title{
IMPROVED DURABILITY OF CONCRETE USING SUPPLEMENTARY CEMENTITIOUS MATERIALS
}

\author{
Banti A. Gedam ${ }^{1}$ (Scientist), Suvir Singh ${ }^{1}$ (Chief Scientist), Akhil Upadhyay ${ }^{2}$ \\ (Professor), and N. M. Bhandari ${ }^{2}$ (Retired Professor) \\ ${ }^{1}$ Fire Research Laboratory, CSIR-CBRI Roorkee, India, Uttarakhand - 247667, \\ bantiagedam@cbri.res.in \\ ${ }^{2}$ Civil Engineering Department, IIT Roorkee, India, Uttarakhand - 247667, \\ akhilfce@iitr.ac.in
}

\begin{abstract}
In the twenty-first century, concrete infrastructures are facing a challenge of how to improve serviceability and sustainability using eco-friendly additives. In fact, to meet such a demand, the concrete structure completely depends on the durability of concrete. However, the conventional normal mix design does not fulfil such demand. Consequently, the concrete structures show deformation or any distress like cracking, etc. during its early service life. Toward this direction, the high-performance concrete (HPC) is looking a good solution. However, due to limited knowledge of structural designer to use of supplementary cementitious materials (SCM) and its influence on the concrete structure, the service life improvement of concrete structures is not always satisfactorily fulfilled. Therefore, in this study, largely extended types of cement and SCMs have been used to prepare HPC mixes. Total nine independent HPC mixes of the M40 to M70 grade were prepared using different SCMs, namely fly ash (FA), silica fume (SF), and ground granulated blast-furnace slag (GGBS) with ordinary Portland cement (OPC) and were investigated their durability by an experimental test setup of permeability. It has observed that the use of SCM with partial replacement of the OPC in concrete is helpful to increase the durability of concrete.
\end{abstract}

Keywords: durability, water permeability test, supplementary cementitious materials, high-performance concrete.

\section{INTRODUCTION}

Today the most important concern of structural engineers is how to construct concrete buildings to meet the variety of demand in respect of durability and economy with environmentally friendly manner. In this regard, HPC seems one of the best options using the variety of economic alternatives cementitious materials, i.e. industrial byproducts like fly ash, silica fume and ground granulated blast furnace slag as partial replacement of ordinary Portland cement. However, such materials when used in different quantities in HPC incorporates different levels of durability and secondary level effects i.e. shrinkage and creep. In this study, only durability problem and solution have been experimentally discussed and the effect of the secondary level study is kept out of scope. More details about the influence of SCMs on the effect of 
secondary level have been very well discussed in the literatures (Gedam at al. 2018, Gedam at al. 2015, Gedam at al. 2014, Gedam at al. 2013). However, many concrete materials, additive/mixture/industrial by-products that are easily available locally and being used in HPC may not ensure durability under severe and demanding environmental conditions. Thus, there is a need to understand the behaviour of HPC, especially using indigenous resources for the satisfactory service life of concrete structures (Mehta and Monteiro 2006).

To address this problem, over the past few decades, a considerable number of studies have been made to improve the life expectancy of concrete structures and which in turn help in the sustainability of resources by delaying its replacement in future. It is evident from the literatures reviewed (Pan et al. 2013; Karthikeyan et al. 2008; Buil and Acker 1985; Nasser and Al-Manaseer 1986; AL-Khaja 1994; Haque 1996; Huo et al. 2001; Zhi-hua and Jiam 2008 and Gesoglu et al. 2009) that the use of supplementary cementitious materials, i.e., FA, SF and GGBS in concrete results in different orders of inherent micro-structural changes. In fact, prediction of such properties by conventional methodology and prescriptive approach would be very difficult because of the great variety of cement and supplementary additives from country to country and different combination used in HPC (ACI 209.2R-08 2008). Therefore, researchers across the world have shown great interest in this problem and have been continuously attempting to improve the understanding and harnessing the benefits in HPC properties. In the present research work, experimental investigation, i.e., water permeability test has been carried out to study the performance and durability of HPC using different SCMs namely FA, SF, and GGBS.

\section{EXPERIMENTATION}

To make the present study more relevant, only indigenous source SCMs available in local condition has been used and its influence on HPC durability studied. The chemical and physical properties of the constituents, HPC mix compositions, and testing details are as below.

\section{Concrete materials}

Chemical compositions and physical properties of cement and different cementitious materials, i.e., OPC, FA, SF, and GGBS used in this study and details are summarized in Table 1. The locally available river sand with the specific gravity of $2.67 \mathrm{~kg} / \mathrm{m}^{3}$, fineness modulus 2.73 and crushed coarse aggregate with maximum particle size 12.5 $\mathrm{mm}$, the specific gravity of $2.70 \mathrm{~kg} / \mathrm{m}^{3}$ and fineness modulus 6.88 have been used.

\section{Concrete mix proportions}

Total nine different compositions of HPC mixes M40 to M70 grade have been designed as per Indian Standard IS: 10262 (2009). The target compressive strength, corresponding to M40 to M70 grade of concrete has been nearly achieved at age 28 days in all cases. The details of HPC mix proportion and total SCM's content are given in Table 2. 
Table 1. Chemical Composition and Physical Properties of OPC and SCM's

\begin{tabular}{|c|c|c|c|c|}
\hline Chemical composition (\%) & OPC & Fly Ash & Silica fume & GGBS \\
\hline $\mathrm{SiO}_{2}$ & 20.8 & 68.1 & 92.4 & 34.3 \\
\hline $\mathrm{Al}_{2} \mathrm{O}_{3}$ & 7.30 & 20.8 & 0.80 & 15.5 \\
\hline $\mathrm{Fe}_{2} \mathrm{O}_{3}$ & 4.20 & 0.90 & 0.82 & 2.07 \\
\hline $\mathrm{CaO}$ & 61.4 & 5.50 & 0.60 & 32.3 \\
\hline $\mathrm{MgO}$ & 2.10 & 0.98 & 1.02 & 7.90 \\
\hline $\mathrm{SO}_{3}$ & 1.20 & 0.24 & 0.23 & 1.88 \\
\hline $\mathrm{K}_{2} \mathrm{O}$ & 0.30 & 0.23 & 0.32 & 0.92 \\
\hline $\mathrm{Na}_{2} \mathrm{O}$ & 0.23 & 0.09 & 0.45 & 1.20 \\
\hline Loss on ignition & 1.00 & 2.18 & 3.07 & 0.88 \\
\hline Insoluble residue & 0.90 & 0.25 & 0.10 & 2.20 \\
\hline $\mathrm{Sum}$ & 99.4 & 99.2 & 99.8 & 99.1 \\
\hline Main compounds & & & & \\
\hline $\mathrm{C}_{3} \mathrm{~S}$ & 33.40 & & & \\
\hline $\mathrm{C}_{2} \mathrm{~S}$ & 34.42 & & & \\
\hline $\mathrm{C}_{3} \mathrm{~A}$ & 12.23 & & & \\
\hline $\mathrm{C}_{4} \mathrm{AF}$ & 12.78 & & & \\
\hline Physical properties & & & & \\
\hline Specific surface area $\left(\mathrm{m}^{2} / \mathrm{kg}\right)$ & 334 & 600 & 20000 & 800 \\
\hline Specific gravity $($ gr/cm & & & \\
\hline Average particle size $(\mu \mathrm{m})$ & 3.15 & 2.4 & 2.2 & 2.9 \\
\hline & 45 & 45 & 0.1 & 2.8 \\
\hline
\end{tabular}

\section{Control specimens and compressive strength}

The experimental study of permeability and mechanical properties testing carried out on, three numbers of test specimens comprising of size $150 \times 150 \times 150 \mathrm{~mm}$ control cube casts at room temperature of $20 \pm 2{ }^{\circ} \mathrm{C}$, de-moulded after 1 day and then cured under controlled water temperature of $27 \pm 2{ }^{\circ} \mathrm{C}$ till the age of 7 and 28 days. The permeability and mechanical testing of HPC cubic specimens have been done as per IS: 3085-1965 (2002) and IS 516-1959 (2004) at age 7 and 28 days to get an idea about the rate of gain of strength and improvement of permeability in different cases. 
Table 2. HPC Mix Proportions for Permeability Measurement

\begin{tabular}{|c|c|c|c|c|c|c|c|c|c|c|}
\hline \multirow{2}{*}{ HPC Mix Composition } & \multirow{2}{*}{ Unit } & \multicolumn{9}{|c|}{ HPC mix proportion } \\
\cline { 3 - 11 } & & Mix-I & Mix-II & Mix-III & Mix-IV & Mix-V & Mix-VI & Mix-VII & Mix-VIII & Mix- IX \\
\hline Grade of concrete & Grade & M40 & M50 & M50 & M50 & M50 & M60 & M60 & M70 & M70 \\
\hline Cement (binder) & $\mathrm{kg} / \mathrm{m}^{3}$ & 340 & 425 & 400 & 420 & 420 & 440 & 450 & 445 & 440 \\
\hline Fly ash & $\mathrm{kg} / \mathrm{m}^{3}$ & 34 & - & 40 & - & - & - & - & - & 44 \\
\hline Silica fume & $\mathrm{kg} / \mathrm{m}^{3}$ & - & - & - & 21 & - & 44 & - & 44.5 & 44 \\
\hline GGBS & $\mathrm{kg} / \mathrm{m}^{3}$ & - & - & - & - & 42 & - & 90 & 89 & - \\
\hline Fine aggregate & $\mathrm{kg} / \mathrm{m}^{3}$ & 681 & 704 & 651 & 663 & 676 & 678 & 614 & 578 & 630 \\
\hline Coarse aggregate & $\mathrm{kg} / \mathrm{m}^{3}$ & 111 & 1150 & 1062 & 1082 & 1103 & 1107 & 1002 & 944 & 1028 \\
\hline Water & $\mathrm{kg} / \mathrm{m}^{3}$ & 153 & 148.75 & 160 & 168 & 151.2 & 135.52 & 129.6 & 144.62 & 137.28 \\
\hline Superplasticizer & $\mathrm{kg} / \mathrm{m}^{3}$ & 2.04 & 1.7 & 1.12 & 4.2 & 3.36 & 3.52 & 3.60 & 7.12 & 7.92 \\
\hline w/(b+c) & - & 0.41 & 0.35 & 0.36 & 0.38 & 0.33 & 0.28 & 0.24 & 0.25 & 0.26 \\
\hline $\mathrm{w} / \mathrm{b}$ & - & 0.45 & 0.35 & 0.41 & 0.40 & 0.36 & 0.31 & 0.29 & 0.32 & 0.31 \\
\hline Slump & $\mathrm{mm}$ & $140 \pm 5$ & $120 \pm 5$ & $120 \pm 5$ & $120 \pm 5$ & $120 \pm 5$ & $120 \pm 5$ & $130 \pm 5$ & $75 \pm 5$ & $75 \pm 5$ \\
\hline$f c k 7$ days & $\mathrm{MPa}$ & 35.85 & 45.33 & 47.62 & 50.07 & 49.77 & 48.44 & 60.02 & 50.36 & 41.66 \\
\hline$f c k$ 28 days & $\mathrm{MPa}$ & 51.70 & 61.18 & 59.03 & 61.18 & 61.78 & 68.73 & 70.96 & 74.37 & 74 \\
\hline
\end{tabular}

Note: $b$ is binder; $c$ is cementitious material; $w$ is water; and $f c k$ is the compressive strength of cube. 


\section{Water Permeability Test}

Durability is an important aspect of HPC and the same has been studied by the water permeability test in all HPC mixes. Total three $150 \times 150 \times 150 \mathrm{~mm}$ cube specimens of each mix have been put under observation for uniaxial water permeability measurements according to IS: 3085-1965 (2002) (see Fig. 1). The specimens were subjected to the water pressure of about $15 \mathrm{~kg} / \mathrm{cm}^{2}$ during the test duration to force the water through the specimens. The measured water quantity passing through the specimen had been used to calculate the coefficient of permeability using Darcy's equation.

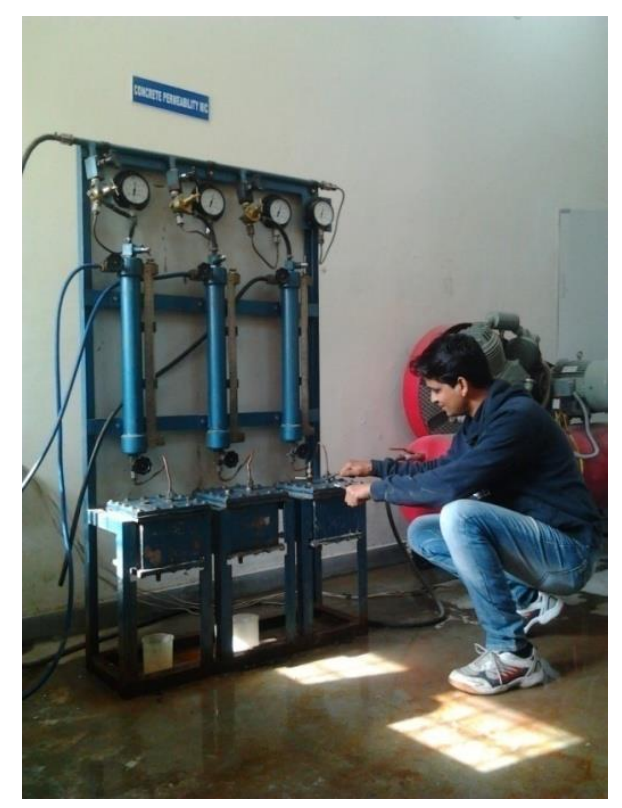

Figure 1. Water permeability test setup for concrete cube specimens

$$
K=\frac{Q}{A T(H / L)}
$$

Where, $K$ is the coefficient of permeability $(\mathrm{cm} / \mathrm{s}), Q$ is the quantity of water in millilitres percolating over the entire period of the test after the steady state has been reached ( $\mathrm{ml}), A$ is the area of the specimen face $\left(\mathrm{cm}^{2}\right), T$ is time in seconds, after which $Q$ is measured (s), $H / L$ is the ratio of the pressure head of thickness of specimens, both expressed in the same units.

\section{RESULT AND DISCUSSION}

The service life of the concrete structure depends on the durability of concrete. It is well known that the inherent microcracks often govern the durability of concrete, probably due to non-uniform chemical/physical/mineralogical composition of cement with SCMs properties, which may affect the concrete durability and make it more vulnerable to micro-cracking. Therefore, to ensure the developed HPC mixes are 
efficiently durable, water permeability test was carried out for each individual HPC Mix.

The hydration phase is important to gain the strength as well as to make concrete more durable, and the same can be better understood by permeability examination. It is observed that the highly heterogeneous nature of HPC properties when studied at water permeability level yields reliable information to understand the influence of SCM's for durable performance. Fig. 2 and Fig. 3 shows the significant improvement in the hardened state of HPC mixes with three different cementitious materials (i.e. FA, SF, and GGBS) in conjunction with an OPC at different maturity periods of 7 days and 28 days.

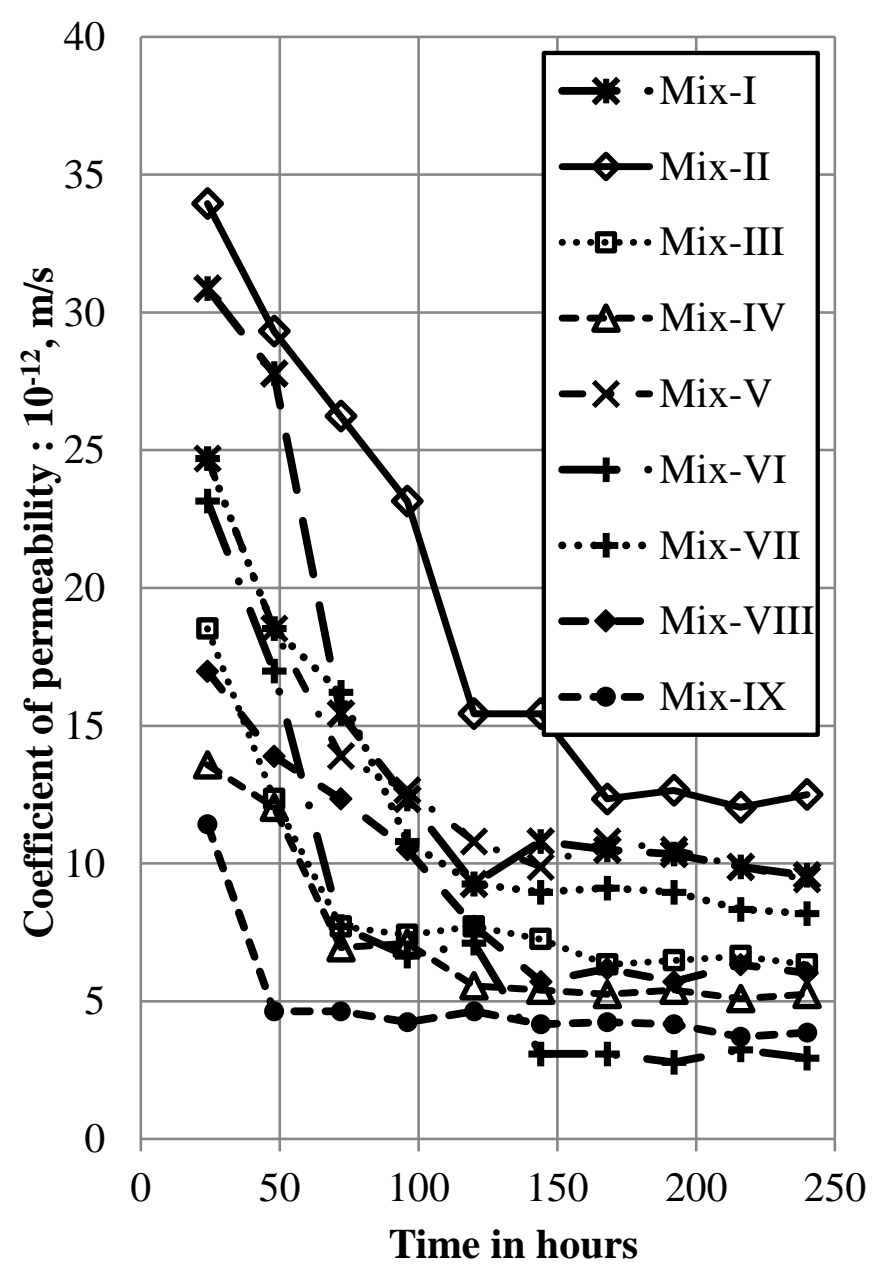

Figure 2. Water permeability coefficient plotted as a function of time in hours for 7 days age HPC mixes

During hydration, Calcium Hydroxide $\mathrm{Ca}(\mathrm{OH})_{2}$ is one of the main hydration products of OPC and partial replacements of the OPC with SCMs are affecting the properties of HPC. These properties are depending upon how well it consumes $\mathrm{Ca}(\mathrm{OH})_{2}$ as a result of pozzolanic activity (Gedam et al. 2015, Papadakis and Pedersen 1999; 
Memon et al. 2002; Papadakis and Tsimas 2002; Elsen 2006). However, due to the pozzolanic activity of $\mathrm{SCM}, \mathrm{Ca}(\mathrm{OH})_{2}$ is converted into secondary calcium silicate hydrate C-S-H gel and its formation increases with maturity age of HPC (Memon et al. 2002; Manmohan et al. 2002). The incremental strength of all HPC mix (Table 2) and performance of permeability due to the pozzolanic activity of cement with SCM is completely different and that same reveal from Fig. 2 and Fig.3.

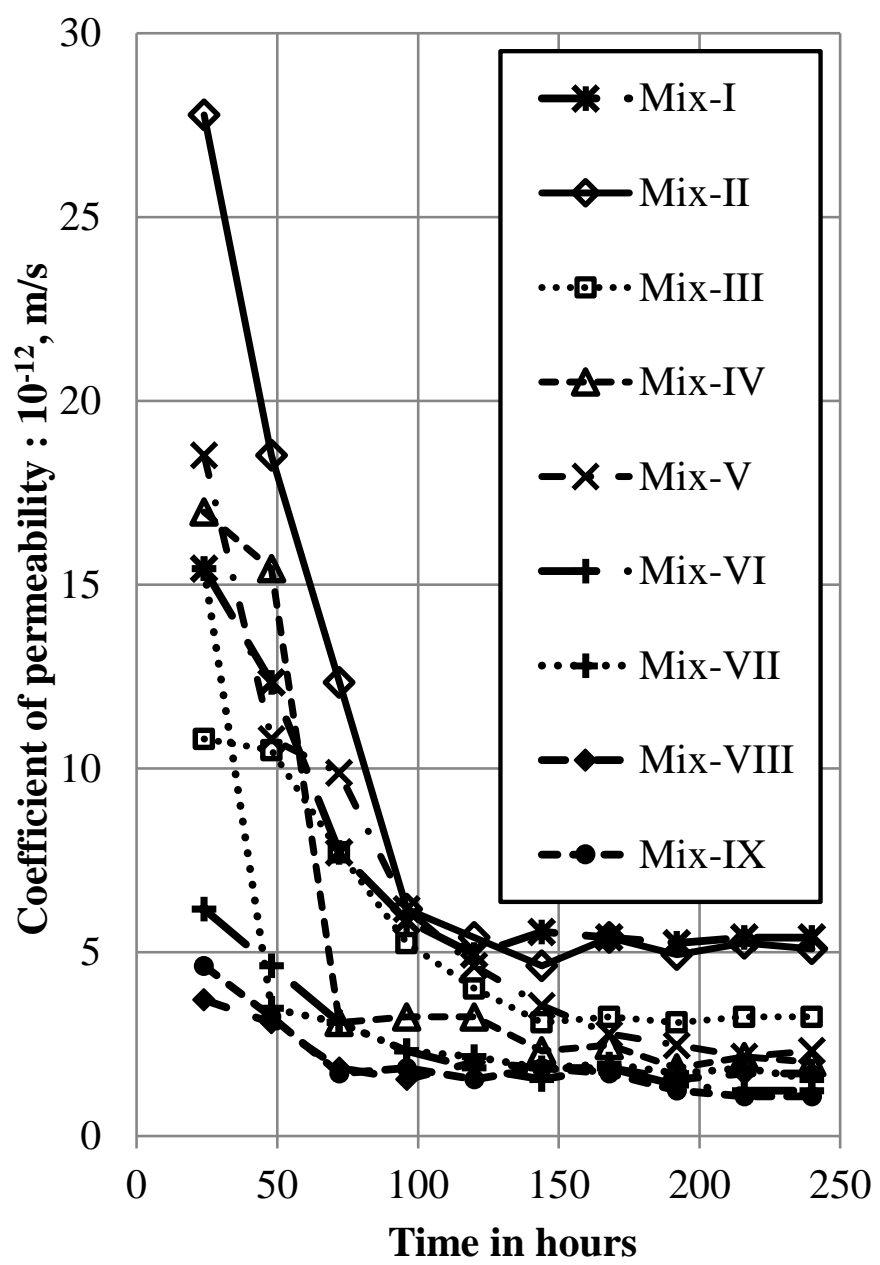

Figure 3. Water permeability coefficient plotted as a function of time in hours for 28 days age HPC mixes

The experimentally measured values of coefficient of permeability at age 7 days and 28 days concrete maturity were recorded after a steady state flow condition is reached. It is seen that in 7 to 10 days after a high initial flow rate the steady state of water flow has been reached and that gives a more stable equilibrium rate of flow in HPC. The test has been continued for 100 hours at the equilibrium rate of flow condition and an average outflow of water of all three specimens of each HPC mix is considered for a coefficient of permeability calculation using a Darcy's equation and the computed results are shown in Table 3 . The test has been conducted on the 7 days and 28 days 
old cubic specimens and continued for 100 hours in each case after the steady state flow of water observed. It has been observed that in water permeability test on each HPC mix, the steady state flow rate condition occurs nearly after 144 hours from commencement of the test, and thus, in general, depending upon the quality of concrete, specimen dimensions, and the technique used for measuring (Neville 1995; Banthia et al. 1992).

Table 3. Coefficient of Permeability

\begin{tabular}{|c|c|c|c|}
\hline \multirow{2}{*}{ HPC Mix } & \multicolumn{2}{|c|}{$\begin{array}{c}\text { Coefficient of permeability } \\
\times 10^{-12}, \mathrm{~m} / \mathrm{s}\end{array}$} & \multirow{2}{*}{$\begin{array}{c}\text { Coefficient of } \\
\text { variation }(\mathrm{CV}), \%\end{array}$} \\
\cline { 2 - 3 } & $\begin{array}{c}\text { Age }=7 \\
\text { days }\end{array}$ & $\begin{array}{c}\text { Age }=28 \\
\text { days }\end{array}$ & \\
\hline Mix-I & 10.07 & 5.36 & 43.17 \\
\hline Mix-II & 12.38 & 5.17 & 58.10 \\
\hline Mix-III & 6.44 & 3.20 & 47.53 \\
\hline Mix-IV & 5.25 & 2.12 & 60.06 \\
\hline Mix-V & 10.15 & 2.43 & 86.79 \\
\hline Mix-VI & 3.01 & 1.43 & 50.33 \\
\hline Mix-VII & 8.64 & 1.76 & 93.56 \\
\hline Mix-VIII & 6.06 & 1.70 & 79.46 \\
\hline Mix-IX & 3.99 & 1.27 & 73.13 \\
\hline
\end{tabular}

It is interesting to note that the coefficient of permeability decreased while the wetcuring period of HPC increased from 7 days to 28 days (Table 3). It is attributed that the extent of chemical bonding of cement with SCMs in concrete affects the coefficient of permeability through the pozzolanic reaction of SCMs which consumed $\mathrm{Ca}(\mathrm{OH})_{2}$ of OPC and converting it to C-S-H gel. According to Neville (1995), Naik et al. (1994), Power et al. (1954), Fraay et al. (1989), and Diamond (2004) this reaction reduces the void space between aggregates and remnants of binding cementitious material. In fact, the use of the finer cementitious material in concrete results in a finer pore size distribution, thus reducing pores, air voids, permeability and increased durability of concrete. Thus the utilization of SCMs in HPC appears to reduce the coefficient of permeability and improves durability dominantly. As seen in Fig. 2 and Fig. 3, HPC mixes containing SF are very fine and highly pozzolanic material, has the fastest reaction with OPC that decreased the coefficient of permeability rapidly with respect to time than of other HPC Mixes.

It is seen that the HPC mixes containing SCMs exhibit decrease a coefficient of permeability at the age of 7 days to that at age of 28 days by a wet-curing (see Table 3). According to Neville (1995) and Mehta and Monteiro (2006) the permeability and diffusion rate of hydration of cement with cementitious material in concrete are relevant probably because of drying the C-S-H gel ratio may rupture some gel between the capillaries and thus its distribution play fundamental role in controlling its properties i.e., mechanical strength and permeability. The HPC Mix-I and Mix-III containing FA at age 28 days decrease $43.17 \%$ and $47.53 \%$ the coefficient of 
variation, Mix-IV and Mix-VI contains SF at age 28 days decrease $60.06 \%$ and 50.33 $\%$ the coefficient of variation, Mix-V and Mix-VII contains GGBS at age 28 days decrease $86.79 \%$ and $93.56 \%$ the coefficient of variation, Mix-VIII contains SF+GGBS and Mix-IX contains SF+FA at age 28 days decrease $79.46 \%$ and $73.13 \%$ the coefficient of variation, and Mix-II contains only cement at age 28 days decrease $58.10 \%$, compared to age 7 day coefficient of variation.

These results indicated that the use of SCMs, i.e., GGBS in HPC produced early age low pozzolanic reaction with OPC than of the FA and SF concrete. Hence, at age 7 days the coefficient of permeability is higher than other HPC mixes, while at age 28 days the coefficient of permeability is lower and shows reduction percentage is higher than other HPC mixes. It is observed in this study that the use of GGBS partial replacement of OPC is the preliminary best option to improve durability as well as the compressive strength of concrete, while the second best option observed that the use of SF. The combination of SF, FA and GGBS with partial replacement of the OPC has also shown a good reduction of the percentage of coefficient of permeability in the Mix-VIII and Mix-IX.

\section{CONCLUSIONS}

In view of the increasing use of SCMs in HPC, this research study presents the influence of the SCMs on permeability and mechanical properties of concrete. The experimental test results show that the partial replacement of cement with different locally available SCM has significantly reduced permeability and improve durability with the maturity of concrete. This research study will be helpful to improve the designer's understanding and incorporate the knowledge in the point of permeability and durability to improve the service life of concrete structures. The following conclusions have been drawn from this research study are:

1. Among the supplementary cementitious materials, i.e., FA, SF, and GGBS, use of GGBS with partial replacement of the OPC in concrete mix design is the best option to reduce permeability and improve a durability as well as compressive strength of concrete.

2. Use of SF with partial replacement of the OPC in concrete is the second best option to reduce permeability and improve a durability as well as compressive strength of concrete.

3. The durability of concrete depends on the pozzolanic reaction of cement with SCM's non-uniform chemical/physical/mineralogical composition and properties.

\section{REFERENCES}

Al-Khaja, W. A. (1994). Strength and time-dependent deformations of silica fume concrete for use in Bahrain. Construction and Building Materials, 8(3):169-172. 
American Concrete Institute Committee 209R-92. (2008). Prediction of creep, shrinkage, and temperature effects in concrete structures. ACI Special Publication, 1-47.

Banthia, N., Pigeon, M., Marchand, J., Boisvert, J. (1992). Permeability of roller compacted concrete. J. Mater. Civ. Eng., 4:27-40.

Banthia, N. (1988). Water permeability of cement paste. Cement and Concrete Research, 19:727-736.

Buil, M., Acker, P. (1985). Creep of a silica fume concrete. Cement and Concrete Research, 15(c):463-466.

Diamond, S. (2004). The microstructure of cement paste and concrete - a visual primer. Cement and Concrete Composites, 26(8):919-933.

Elsen, J. (2006). Microscopy of historic mortars-a review. Cement and Concrete Research, 36(8):1416-1424.

Fraay, A.L.A., Bijen , J.M., Haan, Y.M. (1989). The reaction of fly ash in concrete a critical examination. Cement and Concrete Research, 19:235-246.

Gedam, B. A., Bhandari, N. M., Upadhyay, A. (2018). Time-dependent behaviour prediction, serviceability and sustainability problems for high-performance concrete bridges. Facing the Challenges in Structural Engineering, Sustainable Civil Infrastructures, 254-264.

Gedam, B. A., Bhandari, N. M., Upadhyay, A. (2015). Influence of supplementary cementitious materials on shrinkage, creep and durability of high-performance concrete. Journal of Materials in Civil Engineering, ASCE, 28(4):04015173.

Gedam, B. A., Upadhyay, A., Bhandari, N. M. (2014). An apt material model for drying shrinkage and specific creep of HPC using artificial neural network. Structural Engineering and Mechanics, Techno-Press, 52(1):99-113.

Gedam, B. A., Upadhyay, A., Bhandari, N. M. (2014). Performance of creep and shrinkage prediction models for normal strength concrete. The Bridge \& Structural Engineer, 43(3):137-148.

Gedam, B. A., Bhandari, N. M., Upadhyay, A. (2014). Life cycle sustainability of concrete structure using high performance concrete. International Conference on Sustainable Civil Infrastructure, ICSCI-2014 CASCE Indian Section, IIT Hyderabad, Telangana, India.

Gedam, B. A., Bhandari, N. M., Upadhyay, A. (2014). Appropriate creep and shrinkage model of HPC for improve life-cycle design. fib-Congress, Mumbai, India.

Gedam, B. A., Upadhyay, A., Bhandari, N. M. (2013). Study of an apt creep and shrinkage prediction model for high performance concrete. 22nd International Conference on Structural Mechanics in Reactor Technology, San Francisco, USA.

Gedam, B. A., Upadhyay, A., Bhandari, N. M. (2013). An apt material model to predict creep and shrinkage behaviour of HPC concrete. Third International Conference on Sustainable Construction Materials and Technologies, At Kyoto, Japan.

Gesoglu, M., Güneyisi, E., Ozbay, E. (2009). Properties of self-compacting concretes made with binary, ternary, and quaternary cementitious blends of fly ash, blast furnace slag, and silica fume. Construction and Building Materials, 23:18471854. 
Haque, M. N. (1996). Strength development and drying shrinkage of high-strength concretes. Cement and Concrete Composites, 18(5):333-342.

Huo, S., Al-omaishi, N., Tadros, M. K. (2001). Creep , shrinkage , and modulus of elasticity of high- performance concrete. ACI Material Journal, 98:440-449.

Indian Standard 10262. (2009). Concrete mix proportioning - guidelines, Bureau of Indian Standards. Bureau of Indian Standards,1-14.

Indian Standard 516-1959. (2004). Method of testing for strength of concrete. Bureau of Indian Standards, Reaffirmed in 2004, 1-24.

Indian Standard 3085-1965. (2002). Permeability of cement mortar and concrete. Bureau of Indian Standards, Reaffirmed in 2002, 1-10.

Karthikeyan, J., Upadhyay, A., Bhandari, N. M. (2008). Artificial neural network for predicting creep and shrinkage of high performance concrete. Journal of Adv. Concr. Tech., 6(1):1-8.

Manmohan, R., Mehta, P. K. (2002). Influence of pozzolanic , slag, and chemical admixtures on pore size distribution and permeability of hardened cement pastes. Cement and Concrete Aggregate, 32:373-377.

Mehta, P. K., Monteiro, J. M. (2006). Concrete microstructure, properties, and materials. Third ed., New Delhi, India.

Memon, A. H., Radin, S. S., Zain, M. F. M., Trottier, J. F. (2002). Effects of mineral and chemical admixtures on high-strength concrete in seawater. Cement and Concrete Research, 32(3):373-377.

Naik, T. R., Singh, S. S., Hossain, M. M., Fellow, P., Science, A. (1994). Permeability of concrete containing large amounts of fly ash. Cement and Concrete Research, 24(5):913-922.

Nasser, K. W., Al-Manaseer, A. A. (1986). Creep of concrete containing fly ash and superplasticizer at different stress/strength ratios. ACI Journal, 668-673.

Nevill, A. M. (1995). Properties of concrete. Fourth Ed., New Delhi, India.

Pan, Z., Li, B., Lu, Z. (2013). Re-evaluation of CEB-FIP 90 prediction models for creep and shrinkage with experimental database. Con. Buil. Mat., 38:1022-1030.

Papadakis, V. G., Tsimas, S. (2002). Supplementary cementing materials in concrete Part I : efficiency and design. Cement and Concrete Research, 32:1525-1532.

Papadakis, V. G., Pedersen, E. J. (1999). An AFM-SEM investigation of the effect of silica fume and fly ash on cement paste microstructure. Journal of Material and Science, 34:683-690.

Power, T. C., Copeland, L. E., Jayes, J. C., Mann, H. M. (1954). Permeability of Portland cement paste. J. A,er. Concr. Inst, 51:285-298.

Vondron, G., Webster, T. (1988). The relationship of polypropylene fiber reinforced concrete to permeability, SP-108. American Concrete Institute, 85-97.

Zhi-hua, C., Jian, Y. (2008). Creep experimental test and analysis of high-performance concrete in bridge. J. Cent. South Ynic. Technol,15:577-581. 